\title{
Alternate Anode Reaction for Copper Electrowinning
}

Gerald L. May

Bill Imrie

Sharon Young

Brent Hisky

Jan Miller

Michael Free

July 2005

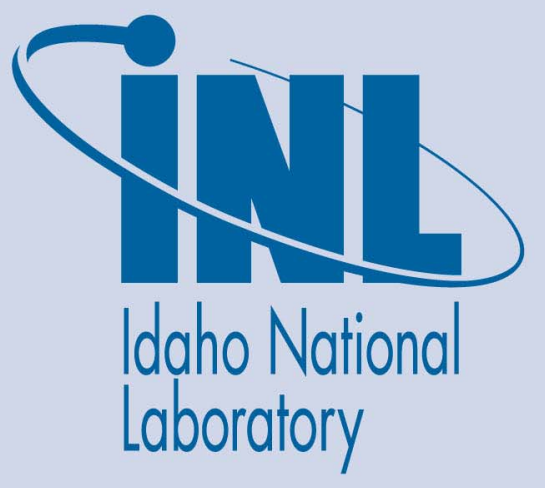

The INL is a U.S. Department of Energy National Laboratory operated by Battelle Energy Alliance 
INL/EXT-05-00539

\section{Alternate Anode Reaction for Copper Electrowinning}

${ }^{a}$ BEA

${ }^{b}$ Bechtel

c Versitec

dUniversity of Arizona

${ }^{\mathrm{e}}$ University of Utah

\author{
Gerald L. May ${ }^{\mathrm{a}}$ \\ Bill Imrie ${ }^{\text {b }}$ \\ Sharon Young ${ }^{c}$ \\ Brent Hisky \\ Jan Miller ${ }^{\mathrm{e}}$ \\ Michael Free
}

July 2005

Idaho National Laboratory

Idaho Falls, Idaho 83415

Prepared for the

U.S. Department of Energy

Office of Nuclear Energy

Under DOE Idaho Operations Office

Contract DE-AC07-05ID14517 


\section{SUMMARY}

This report describes a project funded by the Department of Energy, with additional funding from Bechtel National, to develop a copper electrowinning process with lower costs and lower emissions than the current process. This new process also includes more energy efficient production by using catalyticsurfaced anodes and a different electrochemical couple in the electrolyte, providing an alternative oxidation reaction that requires up to $50 \%$ less energy than is currently required to electrowin the same quantity of copper.

This alternative anode reaction, which oxidizes ferric ions to ferrous, with subsequent reduction back to ferric using sulfur dioxide, was demonstrated to be technically and operationally feasible. However, pure sulfur dioxide was determined to be prohibitively expensive and use of a sulfur burner, producing $12 \% \mathrm{SO}_{2}$, was deemed a viable alternative. This alternate, sulfer-burning process requires a sulfur burner, waste heat boiler, quench tower, and reaction towers. The electrolyte containing absorbed $\mathrm{SO}_{2}$ passes through activated carbon to regenerate the ferrous ion. Because this reaction produces sulfuric acid, excess acid removal by ion exchange is necessary and produces a low concentration acid suitable for leaching oxide copper minerals. If sulfide minerals are to be leached or the acid unneeded on site, hydrogen was demonstrated to be a potential reductant.

Preliminary economics indicate that the process would only be viable if significant credits could be realized for electrical power produced by the sulfur burner and for acid if used for leaching of oxidized copper minerals on site. 


\section{CONTENTS}

SUMMARY

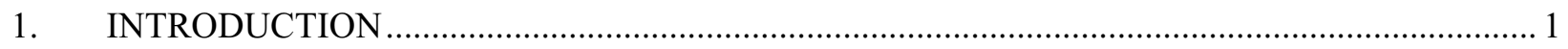

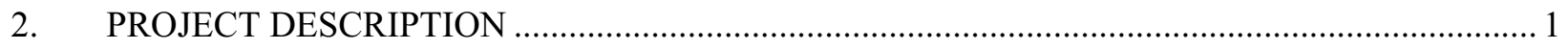

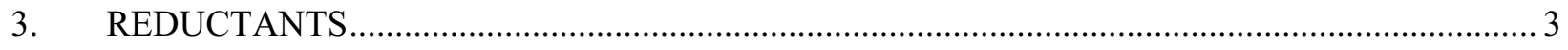

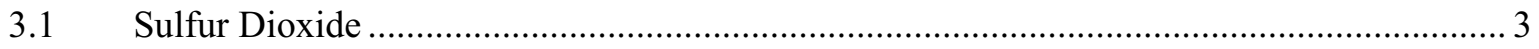

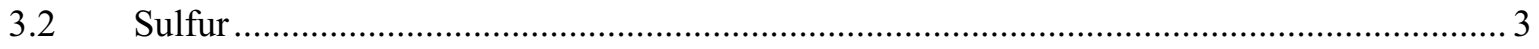

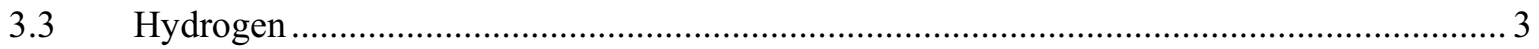

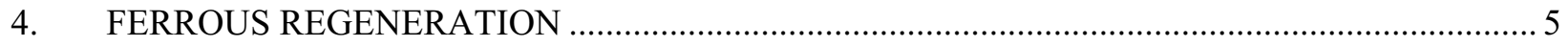

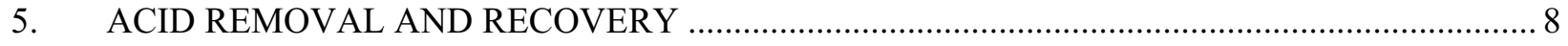

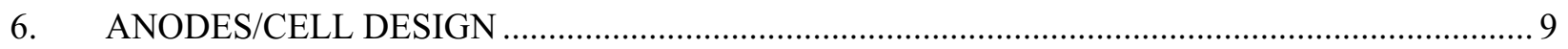

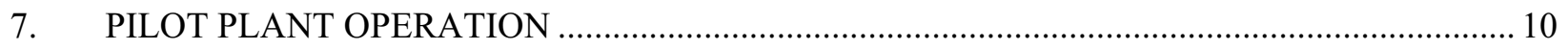

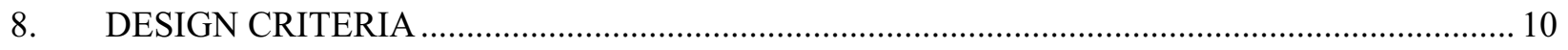

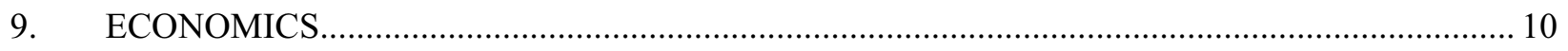

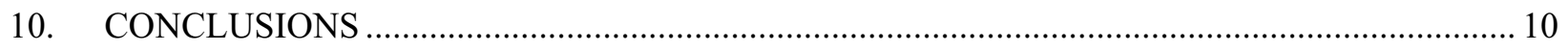

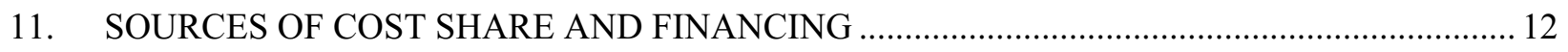

\section{FIGURES}

1. Simplified diagram for economic model........................................................................... 2

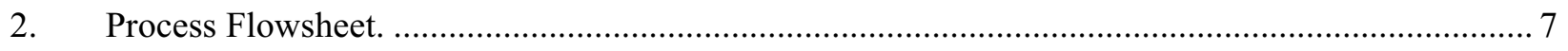

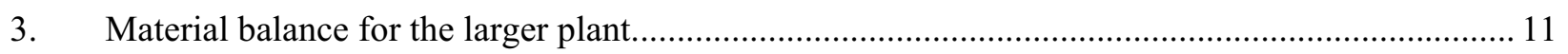




\section{Alternative Anode Reaction for Copper Electrowinning}

\section{INTRODUCTION}

Solvent extraction and electrowinning (SX/EW) are among the most important processes used in the copper industry and are key components in producing some of the best quality copper in the market.

The conventional copper electrowinning process uses the water hydrolysis reaction as the anodic source of electrons. However, this reaction generates acid and oxygen gas. The oxygen, which leaves the system, is associated with some acid from the electrolyte resulting in an acid mist. This mist poses potential health hazards near the electrowinning process. The acid generated also presents corrosion problems. The cell voltages applied for this process are high and because energy consumption is directly proportional to cell voltage, the energy consumption is also high.

The goal of the project documented in this report was to develop a process with lower costs and lower emissions that would include more energy efficient production by using catalytic surfaced anodes and a different ionic couple in the electrolyte, providing an alternative oxidation reaction that requires up to $50 \%$ less energy to electrowin the same quantity of copper. An additional goal was to have the ability to readily retrofit this process into existing commercial copper electrowinning tankhouses as well as incorporate it into new installations

The project resulted in a proposed process that will function without producing acid mist, thus significantly reducing corrosion of buildings and equipment, and requiring less maintenance. The new process will also improve the safety and work environment, and eliminate worker exposure, as it produces no oxygen, acid mist, or other gaseous emissions. The project included a demonstration of the new process at large pilot-plant scale. However, preliminary economics indicate that the process would only be viable if significant credits could be realized for electrical power produced by the sulfur burner and for acid if used for leaching of oxidized copper minerals.

This report includes descriptions and analyses of the project, including the proposed process and the process economics as well as conclusions drawn from the project data.

\section{PROJECT DESCRIPTION}

The proposed technology will employ a reaction that relies on the ferrous/ferric/sulfur dioxide (FFS) chemical species in the copper electrowinning process. The original project planning calls for the FFS technology to be developed for commercialization, focusing on production of sulfur dioxide for ferric reduction, reaction of the resulting gas with the ferric ions to produce acid, removal and recovery of the excess sulfuric acid, and development of anode materials and electrolyte flow manifold design. The research project included a large pilot-plant scale process demonstration at a commercial electrowinning plant. The energy required to produce copper using the FFS process instead of present electrowinning technology was quantified as part of the project.

The FFS process involves the addition of ferrous sulfate to conventional copper electrolyte and the use of catalytic anode surfaces. The anode reaction during electrowinning then becomes the $\mathrm{Fe}^{2+} / \mathrm{Fe}^{3+}$ couple. Separate from the electrowinning cell, ferrous ions are regenerated using gaseous $\mathrm{SO}_{2}$ and forming $\mathrm{H}_{2} \mathrm{SO}_{4}$ as a potentially valuable by-product (e.g., to use onsite for leaching of ore). The diagram in Figure 1 outlines the FFS process. 


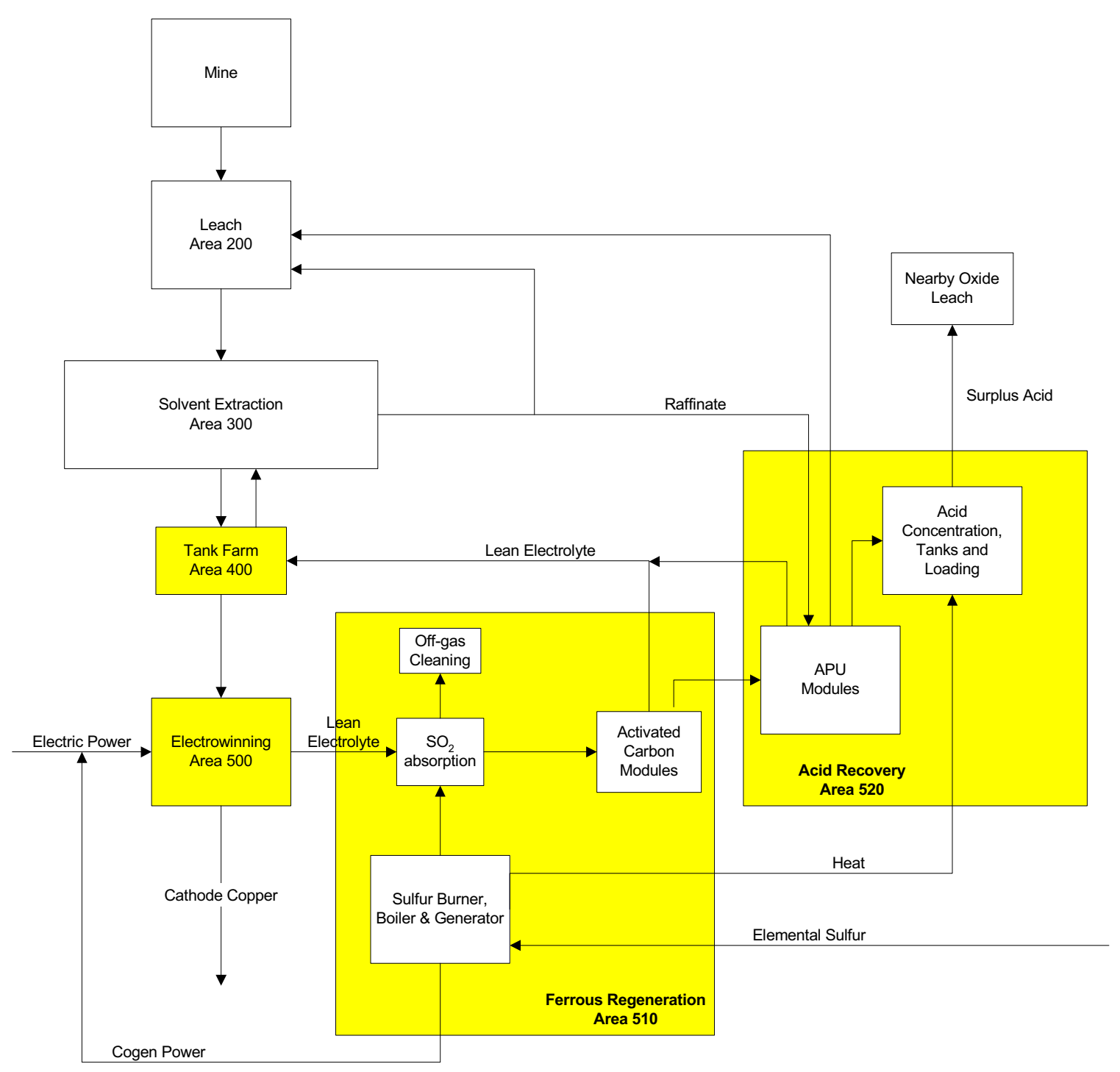

ALTERNATIVE ANODE REACTION FOR COPPER ELECTROWINNING

Figure 1. Simplified diagram for economic model.

The excess acid recovered is quite dilute compared to commercial grade acid and must be used in the immediate vicinity of the electrowinning plant for leaching of additional copper. Excess acid is only consumed with the leaching of oxidized copper minerals in alkaline host rock. Host rock in the southwestern USA is usually quite alkaline and can readily consume the excess acid produced. However when sulfide copper minerals are leached, the leaching process itself produces acid. The cost of producing and recovering unusable acid is therefore a fatal flaw for the economics of the process. The project therefore included investigating other potential reductants as well as the potential of upgrading the sulfuric acid to a salable product. However, the project was based on the FFS process. 


\section{REDUCTANTS}

\subsection{Sulfur Dioxide}

Sulfur dioxide is a versatile compound; in the presence of a strong oxidant it plays the role of a reducing agent, while in the presence of a strong reductant it acts as an oxidizing agent. Since ferric ions are stronger oxidants than sulfur dioxide, this oxide of sulfur is good for the reduction of ferric ions in the solution and is the reaction that provided the basis for the original process development. The reaction proceeds quickly in the presence of activated carbon as a catalyst, most likely in much less than two minutes. The overall reduction reaction using sulfur dioxide is:

$2 \mathrm{Fe}^{3+}+\mathrm{SO}_{2}+2 \mathrm{H}_{2} \mathrm{O}=\mathrm{H}_{2} \mathrm{SO}_{4}+2 \mathrm{H}^{+}+2 \mathrm{Fe}^{2+}$

The above reaction also indicates that one mole of $\mathrm{SO}_{2}$ is needed to remove one mole of copper. One mole of excess $\mathrm{H}_{2} \mathrm{SO}_{4}$ is generated per mole of copper removed from the solution.

The effect of oxygen on this reduction mechanism was evaluated due to the presence of significant amounts of residual oxygen in $\mathrm{SO}_{2}$ gas streams produced by sulfur burners. The gas mixtures used in these tests were composed of sulfur dioxide and oxygen (total $20 \%$ by volume) with the balance consisting of nitrogen.

Results of sulfur dioxide and oxygen tests showed that some the ferric ions are regenerated if the gas contains oxygen. The predicted results showed that $21 \%$ of the sulfur dioxide consumed will be utilized to counteract the effect of oxygen when the gas mixture consistes of $12.37 \% \mathrm{SO}_{2}+7.96 \% \mathrm{O}_{2}$ with the balance consisting of nitrogen. This value reduces to $7.69 \%$ with a gas mixture of composition $17.91 \% \mathrm{SO}_{2}+2.01 \% \mathrm{O}_{2}$ with the balance consisting of nitrogen.

\subsection{Sulfur}

The overall reduction reaction using elemental sulfur can be expressed as:

$6 \mathrm{Fe}^{3+}+\mathrm{S}^{\mathrm{o}}+4 \mathrm{H}_{2} \mathrm{O}=\mathrm{H}_{2} \mathrm{SO}_{4}+6 \mathrm{H}^{+}+6 \mathrm{Fe}^{2+}$

Elemental sulfur can give up to six electrons, which is sufficient to reduce six ferric ions. Since two $\mathrm{Fe}^{3+}$ are required to remove one $\mathrm{Cu}^{2+}$, each elemental sulfur atom will be sufficient to enable the production of three copper atoms. This reaction also shows that the excess $\mathrm{H}^{+}$produced is one mole of acid for each three moles of $\mathrm{Cu}$ produced or one-third of the excess acid produced by the $\mathrm{SO}_{2}$ reduction.

During the study of sulfur as a reducing agent, orthorhombic and liquid sulfurs were used. The results show that sulfur reduces the ferric ion concentration from $1.5 \mathrm{~g} / \mathrm{L}$ to approximately $0.04 \mathrm{~g} / \mathrm{L}$ in two hours at $100^{\circ} \mathrm{C}$, or to $0.1 \mathrm{~g} / \mathrm{L}$ in four hours at $50^{\circ} \mathrm{C}$. Thus, sulfur offers significant potential as a ferric ion reductant.

\subsection{Hydrogen}

Hydrogen is used for reduction of metal ions in many metallic systems. It is a logical choice as a candidate for ferric ion reduction. However, there is an explosion risk associated with the hydrogen gas. The overall ferric ion reduction reaction using hydrogen gas is:

$2 \mathrm{Fe}^{3+}+\mathrm{H}_{2}=2 \mathrm{H}^{+}+2 \mathrm{Fe}^{2+}$ 
The application of hydrogen as a reductant is widely known. In this study, the reduction of ferric ions with hydrogen was investigated using various catalysts such as graphite and platinum. Specifically, various forms of graphite (natural, synthetic, and exfoliated) and platinum (amorphous and crystalline) particles were evaluated at different concentrations and size distributions.

One of the most effective surfaces evaluated in this study for the reduction of ferric ions in the presence of hydrogen gas is crushed graphite electrode particles. The normalized reduction rate for these particles in the $20 \times 60$ mesh sample that was present in electrolyte solution containing $5 \mathrm{~g}$ particles $/ \mathrm{L}$ concentration is 1.49 grams of ferric ions reduced per liter of electrolyte per hour per square meter of particle surface per liter of hydrogen gas used.

Natural graphite flakes and exfoliated graphite particles were also used as potential catalytic surfaces to enhance the ferric reduction process with hydrogen gas. However, all testing with these substances was subject to inadequate mixing due to surface hydrophobicity that caused the material to float when exposed to the injected argon-hydrogen gas mixture. Consequently, effective contact between the electrolyte and the surfaces was minimal and the reduction rates were also negligible. No surfactant was added to enhance the wettability for these tests.

Colloidal graphite was evaluated with and without surfactant present to aid in particle wetting. However, because the colloidal graphite is extremely hydrophobic, the introduction of $2 \%$ hydrogen in argon gas causes flotation to occur and the colloidal graphite does not have sufficient wettability to sustain a significant ferric ion reduction rate.

Synthetic graphite in various sizes was evaluated as a potential catalytic surface for ferric ion reduction. Graphite particles (-200 mesh) produced synthetically from desulfurized petroleum coke were evaluated and found to produce significant ferric ion reduction in the copper electrowinning electrolyte. The normalized rate of reduction was approximately 0.5 grams of ferric reduced per liter of solution per hour per square meter of catalytic surface area per liter of hydrogen gas.

Graphite particles (-20+100 mesh) were also tested. The larger particles also gave significant reduction rates of between 0.059 and 0.8 grams of ferric reduced per liter of solution per hour per meter squared of external surface area per liter of hydrogen gas.

Thus, hydrogen gas was found to carry out the ferric reduction reaction effectively even when used in the very small concentration of $2 \%$ by volume. The presence of graphite as a catalyst for this reaction greatly improves the rate. Extrapolation from bench scale tests suggested that hydrogen reduction of ferric ions might be feasible on a commercial scale. Graphite and platinum were found to be the most effective catalysts in carrying the ferric ion reduction by hydrogen gas. Platinum catalyzed the process when used in amorphous form as well as in the form of a supported catalyst on graphite.

Platinum-coated graphite was evaluated to determine if the presence of platinum on the graphite particles enhanced the ferric ion reduction process in the presence of $2 \%$ hydrogen gas in argon. The platinum was coated by electrolysis deposition. However, a complete coating was not achieved. The test results showed a significant normalized rate of reduction occurred (2.58 grams of $\mathrm{Fe}^{3+}$ reduced per liter of solution per hour per meter square of catalyst surface area per liter of hydrogen gas).

The cost analysis for the use of ferric/ferrous reaction along with hydrogen as a reductant is discussed below. The electrical energy saved by shifting from water hydrolysis to ferrous/ferric reaction can be calculated as 


$$
E=\frac{26800 \cdot V \cdot n \cdot}{M_{w} \cdot \beta}
$$

where $E$ is electrical energy saved in $\mathrm{kWh} /$ ton of copper, $\mathrm{n}$ is number of electrons, $\mathrm{M}_{\mathrm{w}}$ is the atomic weight of copper, $\mathrm{V}$ is the voltage reduction and $\beta$ is the current efficiency.

For a voltage reduction of $1.0 \mathrm{~V}$ operating at a current efficiency of $95 \%$, the energy savings will be:

$$
E=\frac{26800 \times 1.0 \times 2}{63.54 \times 0.95}=665.98 \mathrm{kWhr} / \text { tonCu }=0.332 \mathrm{kWhr} / \mathrm{lbCu}
$$

In the United States, on a national level, the average price for electrical energy in 2001 was 7.32 cents $/ \mathrm{kWhr}^{1}$ and the average price for electricity for the industrial sector was $5.04 \mathrm{cents} / \mathrm{kWhr}^{2}$. Hence, using this data, the total savings obtained by shifting from water hydrolysis to ferrous/ferric reaction is 1.67 cents/lb of $\mathrm{Cu}$.

The hydrogen required for the process can be obtained from an onsite natural gas reformer, which will cost around 34 cents/lb of $\mathrm{H}_{2}{ }^{3}$. Since one mole of hydrogen will give one mole of copper at cathode in electrowinning, the investment for the onsite supply of hydrogen will be 1.08 cents/lb of $\mathrm{Cu}$.

The difference between the cost savings using hydrogen $(1.67 \notin / \mathrm{lb})$ and the cost of hydrogen $(1.08 \notin / \mathrm{lb})$ is $0.59 \notin / \mathrm{lb}$ of $\mathrm{Cu}$.

\section{FERROUS REGENERATION}

Sulfur dioxide has been shown to react with ferric ion in copper electrolyte according to the reaction:

$2 \mathrm{H}_{2} \mathrm{O}+\mathrm{SO}_{2}+2 \mathrm{Fe}^{3+} \rightarrow 2 \mathrm{Fe}^{2+}+\mathrm{SO}_{4}^{2-}+4 \mathrm{H}^{+}$

The electrolyte typically contains $160 \mathrm{~g} / \mathrm{L} \mathrm{H}_{2} \mathrm{SO}_{4}, 40 \mathrm{~g} / \mathrm{L} \mathrm{Cu}^{2+}, 27 \mathrm{~g} / \mathrm{L} \mathrm{Fe}^{2+}$, and $3 \mathrm{~g} / \mathrm{L} \mathrm{Fe}^{3+}$. The reaction is catalyzed by activated carbon.

When combined with copper electrowinning using ferrous oxidation as the anode reaction, the overall reaction becomes:

$\frac{\text { Electrowinning: } \mathrm{CuSO}_{4}+2 \mathrm{Fe}^{2}+\rightarrow \mathrm{Cu}^{0}+2 \mathrm{Fe}^{3+}+\mathrm{SO}_{4}^{2-}}{\text { Overall Reaction: } \mathrm{CuSO}_{4}+2 \mathrm{H}_{2} \mathrm{O}+\mathrm{SO}_{2} \rightarrow \mathrm{Cu}^{0}+2 \mathrm{H}_{2} \mathrm{SO}_{4}}$

A key to making this process work is reacting $\mathrm{SO}_{2}$ with $\mathrm{Fe}^{3+}$ in copper electrolyte. Bench and pilotscale work passed a pure $\mathrm{SO}_{2}$ gas/electrolyte mixture through a module of activated carbon, where a quick conversion of $\mathrm{SO}_{2}$ to $\mathrm{H}_{2} \mathrm{SO}_{4}$ was achieved. The use of pure $\mathrm{SO}_{2}$ to reduce the ferric ion has been demonstrated to be uneconomical. On an industrial scale, producing $\mathrm{SO}_{2}$ from sulfur in such a way that the $\mathrm{SO}_{2}$ can be utilized in this process is the issue. The $\mathrm{SO}_{2}$ can be produced from burning sulfur in air. The $\mathrm{SO}_{2}$ must then be transferred from the resulting nitrogen-oxygen- $\mathrm{SO}_{2}$ gas mixture into copper electrolyte, and passed through the activated carbon. As discussed above, sufficient oxygen will be absorbed into the electrolyte to oxidize $\mathrm{Fe}^{2+}$, making the process less efficient by about $20 \%$. A provision 
to scrub the large volume of nitrogen/oxygen gas mixture to remove residual $\mathrm{SO}_{2}$ before emitting to the atmosphere must be considered.

The goal for a 175,000 ton/year copper production plant is to emit less than 40 tons $\mathrm{SO}_{2} /$ year into the atmosphere. Since approximately one ton of $\mathrm{SO}_{2}$ is required for each ton of copper produced, less than $0.02 \%$ of the $\mathrm{SO}_{2}$ produced can be emitted or less than an overall average of about $25 \mathrm{ppm}$ in the exiting gas if the burner gas contains $12 \% \mathrm{SO}_{2}$.

The portion of the flowsheet to be developed consists of the introduction of molten sulfur to the sulfur burner, producing gas containing $\mathrm{SO}_{2}$ to be introduced into the electrolyte and reaction of the $\mathrm{SO}_{2}$ with the ferric ion to produce ferrous ion and acid. The flowsheet is shown in Figure 2.

A sulfur burner can provide a wide range of $\mathrm{SO}_{2}$ strengths, typically from 8-12\%. A higher strength gas has the advantage of less air required thus increasing the available heat, reducing excess oxygen, and reducing the amount of inert gas to be treated prior to exiting the system. Less oxygen reduces the possibility of oxidizing a portion of the ferrous ion outside of the ferric reduction reaction. However, if the concentration of the $\mathrm{SO}_{2}$ is much above $12 \%$, the gas becomes very corrosive, in part due to the formation of some sulfur trioxide. The formation of the trioxide also has a significant negative effect on the economics as more sulfur is required to provide sufficient sulfur dioxide and more acid must be removed from the electrolyte. Different and much more expensive materials of construction are also required for the plant. Therefore the flowsheet was developed around a gas concentration of $12 \% \mathrm{SO}_{2}$.

The hot gas exiting the sulfur burner will pass through a waste heat boiler to produce steam for power generation and secondary steam suitable for process uses. The gas will then go to a humidifying or quench tower that will further cool the gas and bring it to near saturation with water to avoid crystallization of the electrolyte.

The $\mathrm{SO}_{2}$ bearing gas and the high ferric lean electrolyte will then enter reaction towers where the $\mathrm{SO}_{2}$ is absorbed into the electrolyte. The gas exiting the towers will pass through a demister to ensure that environmental regulations are met. The reaction towers may be conventional towers, 10 each of $10 \mathrm{ft}$. diameter, each equipped with 12 feet of packing, operated in parallel for both gas and electrolyte flows. The budgetary price for the reaction towers alone is $\$ 1,700,000 \pm 25 \%$.

A potential alternative is Monsanto's DynaWave reactors in which the gas is treated in two counter current reactors before being demisted. Without a contract assuring confidentiality and agreement to purchase their product, Monsanto would not provide costs of such reactors but indicated that the sulfur burner, waste heat boiler, humidifying tower and reaction towers should be order-of-magnitude $\$ 7,000,000$ installed.

The electrolyte will then pass through activated carbon modules. The design was based on a fiveminute retention time. Several vendors were contacted and they indicated they could not supply an effective system (with estimates of from 33 to over 150 vessels being deemed necessary) with enough capacity for the 5-minute retention time for $66,000 \mathrm{gpm}$. One vendor suggested he could provide a nonconventional system, but would require an agreement that he would provide the commercial unit(s). Nichem was the only one to indicate they thought what was requested was feasible. They worked with another company, AFT, to come up with a design and budgetary prices for the activated carbon modules, resulting in two $80 \mathrm{ft}$ diameter mix tanks, constantly stirred by paddles, and each containing approximately $60,000 \mathrm{lb}$. of activated carbon. Spent carbon is removed from these tanks by vibrating screens. The spent carbon is reactivated by a rotary kiln and is fed to a feed tank for make-up to the mix tanks. To minimize attrition, it is recommended that a coconut shell-based carbon be used instead of a 


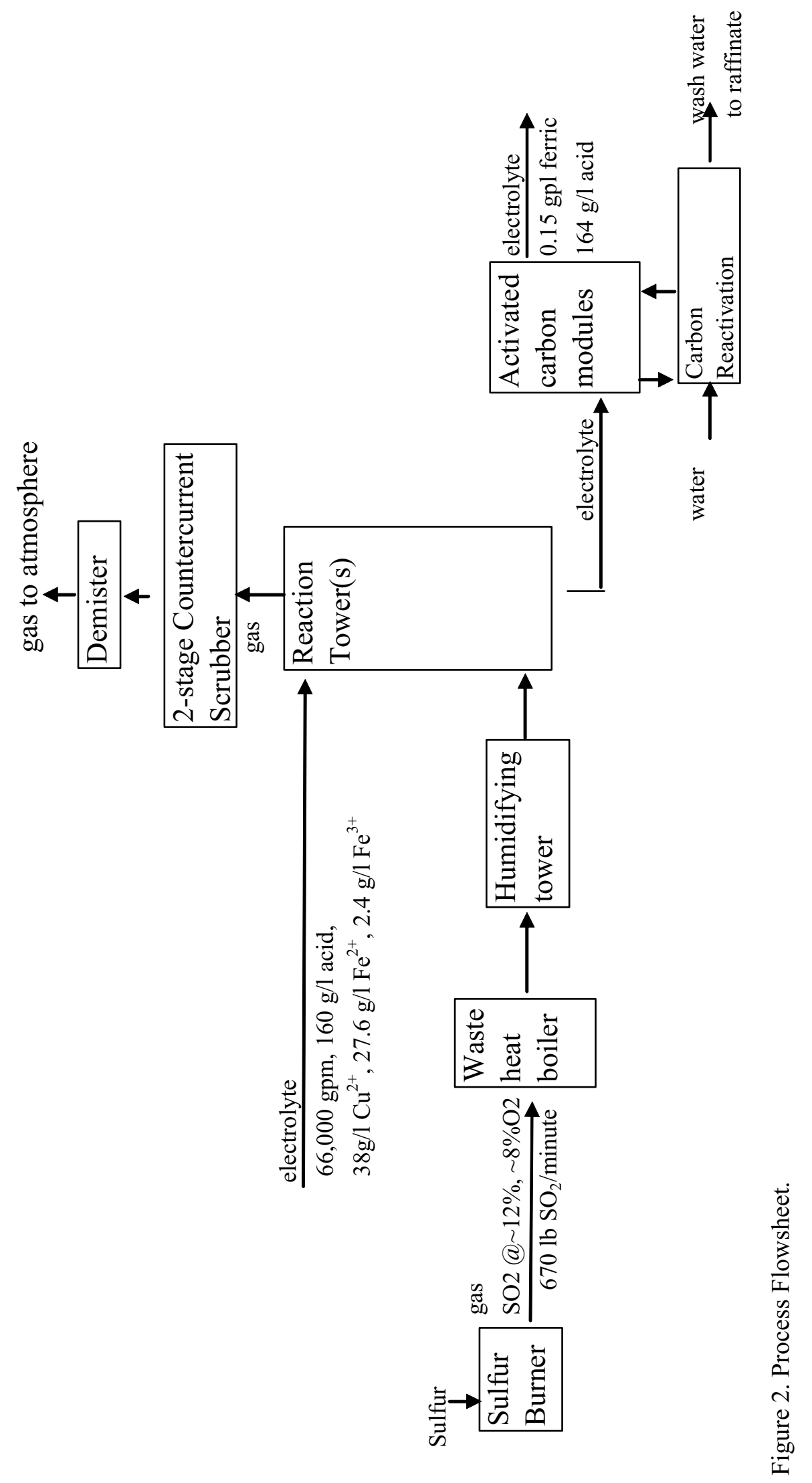


coal-based carbon. Following carbon contact, the electrolyte will need to be filtered to remove carbon fines with DE precoat rotary vacuum filters. Ten (10) filters are required for the 66,000-gpm-electrolyte flow. The electrolyte equipment is estimated at $\$ 3,900,000 \pm 25 \%$ and includes the following:

- $\quad$ One initial activated carbon fill $(120,000 \mathrm{lb})$

- $\quad$ Two ea. $80 \mathrm{ft}$ diameter mix tanks, site built concrete

- $\quad$ Two ea. 200 HP low speed bridge mount mixers

- Two ea. $60 \mathrm{ft}$. diameter strip/recycle tanks

- $\quad$ One $15 \mathrm{ft}$ diameter spent carbon tank

- $\quad$ One direct fired rotary kiln

- $\quad$ One $8 \mathrm{ft}$ diameter quench tank with fines carryover

- $\quad$ One lot process water recycle system from contactors

- $\quad$ One lot 1,200 ft 24 in. diameter carbon steel piping and flanges

- 1 lot process water valves of varying diameters

- $\quad 10$ ea. stainless steel rotary vacuum filters

The retention time in the carbon modules can probably be reduced to less than two minutes from the five minutes originally used for sizing. Decreasing the capital costs of the carbon modules and carbon regeneration system by $50 \%$ gives an equipment cost of $\$ 2 \mathrm{M}$. A factor of 2.5 is used to convert equipment costs into installed costs of $\$ 5 \mathrm{M}$.

The capital costs for the ferrous regeneration system are given below. The annual carbon replacement costs are estimated to be $120,000 \mathrm{lb} \times 20 \%$ x $\$ 0.60$ or about $\$ 15,000$.

\begin{tabular}{|l|c|}
\hline & Installed \\
\hline Sulfur burner, WHB, Quench Tower, & \\
\hline Reaction Towers and Demister & $\$ 7 \mathrm{M}$ \\
\hline Activated Carbon Modules and Filters & $\$ 5 \mathrm{M}$ \\
\hline Total & $\$ 12 \mathrm{M}$ \\
\hline
\end{tabular}

\section{ACID REMOVAL AND RECOVERY}

It was necessary to evaluate, assess, and recommend processes and equipment required to effectively remove sulfuric acid produced from the sulfur dioxide reduction step of the process and prepare the installed costs of said equipment. Secondly, it was necessary to provide an effective pilot unit for plant acid retardation test work. Third, equipment was identified that could be used to upgrade the extracted sulfuric acid to a concentration of greater than $300 \mathrm{~g} / \mathrm{L}$. 
Three suppliers were identified that can provide equipment for the removal of sulfuric acid from the process stream. The recovery and cost of the three vary significantly. The acid recovery ranges from $72.5 \%$ to $94.2 \%$ of the input acid and installed costs range between approximately $\$ 29$ and $\$ 42$ million dollars. The table below summarizes the acid recovery as well as the copper and iron losses for each piece of equipment.

\begin{tabular}{|l|c|c|c|}
\hline & Acid Recovery & Copper Loss & Iron Loss \\
\hline Higgins Loop & $94.2 \%$ & $4.2 \%$ & $6.4 \%$ \\
\hline MPT/Ari & $85.0 \%$ & $12.8 \%$ & $12.9 \%$ \\
\hline EcoTec & $72.5 \%$ & $11.1 \%$ & $12.0 \%$ \\
\hline
\end{tabular}

Each of the three suppliers have pilot plants that are available for onsite rental testing. The reason for determining the efficiency and cost of the full sized plant was to identify one system, which was more cost effective than the others and then obtaining a pilot plant unit that would verify the stated results. Rental costs ranged between $\$ 50,000$ and $\$ 250,000$. During the course of identifying pilot plants, Phelps Dodge purchased individual components for use in their test facility and proceeded forward with their own pilot test work from which no test results are available.

The discharge acid concentration from the three pieces of equipment, previously stated, ranged between 110 and $193 \mathrm{~g} / \mathrm{L}$, far below the requested $300 \mathrm{~g} / \mathrm{l}$. Various evaporators and membrane processes were investigated to determine if the concentration to $300 \mathrm{~g} / \mathrm{l}$ was possible to obtain.

Nine different evaporator types and manufacturers were contacted and all but two said that the units for which information was requested were larger than they had ever made. All who had experience with submerged combustion burners stated that this process is not the correct application for the submerged flame and there would be additional costs associated with environmental containment of the discharge. The most practical unit is a two-stage falling film MVR (mechanical vapor recompression) evaporator, which will produce the required acid concentration and provide purified water back to the process.

Three different membrane units were identified but none were capable of producing the $300 \mathrm{~g} / \mathrm{l}$ acid concentration required. The problem is that the viscosity of the acid solution changes and would become more like honey or thick syrup and would not pass through the membrane. Heat would be required to allow the solution to pass through the membrane and Hastalloy $\mathrm{C}$ or Carpenter 20 would be the material of construction making the units too costly for commercial installation.

It was determined that the membrane equipment could be used cost effectively to recover copper and iron that would pass through the acid removal unit and out of the process flow unless a secondary metal recovery step was installed. Estimates indicated that $98 \%$ of the copper and $97 \%$ of the iron could be recovered from the discharge stream.

\section{ANODES/CELL DESIGN}

Earlier testwork and experience of some of the team members indicated that anode and cell designs needed significant improvement. At the outset of the project, Phelps Dodge indicated that they would do this development work and considered it proprietary and confidential. Phelps Dodge personnel indicated that they had been successful. No other information was provided. 


\section{PILOT PLANT OPERATION}

Phelps Dodge Morenci has a four-cell pilot plant, which was to be used as the demonstration plant. Their personnel indicated that they considered its operation and the information derived to be proprietary and confidential. No data or information was provided other than that they had had a successful pilot plant run of several months and achieved the expected decrease in cell voltage. No comments were made concerning the cell design nor offset costs of electrolyte pumping.

\section{DESIGN CRITERIA}

A flowsheet with material balance was developed for a plant producing 175,000 TPY and for a smaller plant producing 50,000 TPY. A rough draft of cell design criteria was prepared for both. Although the project originally was concerned with the larger plant, it is much more likely that a first commercial operation would be the smaller plant size. The material balance for the larger plant is presented in Figure 3.

\section{ECONOMICS}

Preliminary calculations of Net Present Value relative to conventional electrowinning gave a negative value of about $\$ 45 \mathrm{M}$. No credit was given to operating costs for electrical power generated by the sulfur burner or for acid that can be used for leaching. Both of these items are highly dependent on the location and type of ore body where the EW plant would be located.

\section{CONCLUSIONS}

- No technical or operational fatal flaws were discovered.

- $\quad$ Sulfur dioxide regeneration of ferrous ions would be the most likely first commercialization if located at an oxide leach property where power costs are high and sulfuric acid availability is limited, giving the best economics. This process is not viable for leach systems that do not required a significant amount of sulfuric acid, such as sulfide mineral leaching.

- Hydrogen is an interesting alternative reductant that should be investigated more thoroughly, especially for sulfide leach applications. This reductant produces no excess acid and would therefore be useful in leaching of all types of copper minerals.

- Sulfur can also act as a reductant. It also produces excess acid but only about one third as much as the sulfur dioxide reductant.

- Using sulfur dioxide produced in a sulfur burner at $12 \% \mathrm{SO}_{2}$ requires a sulfur burner, waste heat boiler, quench tower, reaction towers, and demister to introduce the reductant into the electrolyte and vent the waste gases to the atmosphere meeting environmental regulations. The residual oxygen will reoxidize ferrous ions causing as much as a $20 \%$ loss in efficiency.

- $\quad$ The electrolyte containing the absorbed sulfur dioxide is passed through activated carbon beds nominally for five minutes. The retention time required is expected to be much less than two minutes.

- $\quad$ The excess acid produced can be recovered by ion exchange and can produce acid ranging from 110 to $190 \mathrm{~g} / \mathrm{L}$ depending on the supplier and configuration of equipment. 


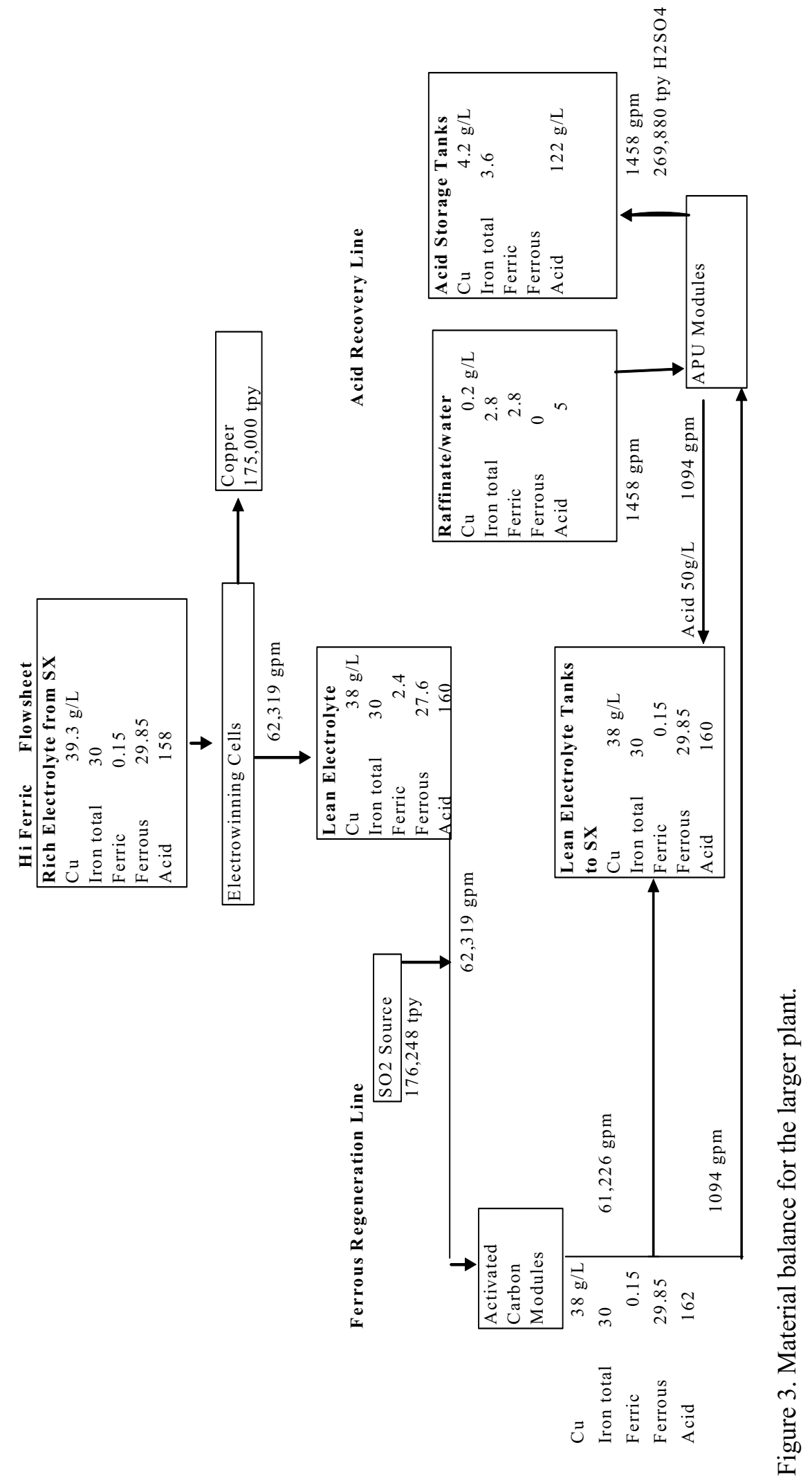


- $\quad$ The most likely method of upgrading acid to $300 \mathrm{~g} / \mathrm{L}$ is by two-stage falling film mechanical vapor recompression evaporation.

- Membrane units can be used cost effectively to recover copper and iron that would be lost with the acid.

- $\quad$ Preliminary economic evaluations indicated that the process would not produce a positive net present value unless significant operating cost credits could be realized by power generation at the sulfur burner and by offsets to leaching acid costs where acid is in short supply and/or very expensive.

\section{SOURCES OF COST SHARE AND FINANCING}

\begin{tabular}{|l|c|c|}
\hline \multicolumn{1}{|c|}{ Project Partner } & In-Kind Contributions & Cash Contributions \\
\hline Bateman Engineering & $\$ 95,000$ & \\
\hline Bechtel International & $\$ 10,000$ & $\$ 120,000$ \\
\hline Phelps Dodge Mining and Phelps Dodge Miami & $>\$ 3,000,000^{\mathrm{a}}$ & \\
\hline Department of Energy & & $\$ 366,963$ \\
\hline Total & $>\$ 3,105,000$ & $\$ 486,963$ \\
\hline a. Phelps Dodge would not provide exact expenses. & \\
\hline
\end{tabular}

